\title{
High Ligation of the Anal Fistula Tract by Lateral Approach
}

\author{
Tzu-An Chen ${ }^{1}$
}

Published online: 13 June 2015

(c) Société Internationale de Chirurgie 2015

To the Editor,

I have read with great interest the recent article by Ye et al. [1] on the experience with the modificated approach of ligation of the intersphincteric fistula tract for high transsphincteric fistula. For the complex fistula with significant proportion of the anal sphincter involved, the ligation of intersphincteric fistula tract (LIFT) procedure appears to be safe and effective and may be routinely considered for complex anal fistula [2,3]. Ye et al. stated that they developed a modified method because of the poor outcomes after performing the classic Thailand LIFT procedures in their institute. Since the LIFT procedure is a well-recognized operation now, I think that their suboptimal results after LIFT procedure should be reviewed.

In 2012, I published a modified operation for high ligation of the fistula tract without damage to the sphincter system and avoiding incision over the intersphincteric plane by lateral approach [4]. Although Ye et al. claimed that their method was contrary to my published operation, I believed that their idea was derived from my report and the concept was basically the same. The goal of high ligation is closing the internal opening of the fistula and blocking the route of infection. My approach places the incision lateral to the external sphincter, well away from the anal verge. I strongly suspect that the perianal location of the classic LIFT incision is a possible reason of postoperative recurrence. By lateral approach, the integrity of anus could be achieved and the prognosis might be better.

Tzu-An Chen

tlalocc@gmail.com

1 Department of Surgery, Taiwan Landseed Hospital, Taoyuan City, Taiwan
The other concern is the ligation method. In my practice, the proximal part of fistula was exposure by traction of the distal part of the track combined with retraction of the external sphincter. High ligation was the key step in the procedure. If the tract was not mature or thick enough, ligation would not be possible. Ye et al. added another procedure after ligation, a stay suture on the internal sphincter side of the tract, for closing the tract opening. In my opinion, it is not necessary if the high ligation was secure. Besides, an additional internal opening might be created if the stitches penetrated through the rectal wall.

A number of new sphincter-preserving techniques have been reported recently, all with the common goal of minimizing the injury to the anal sphincters and optimizing the functional outcome. Above of all, high ligation of fistula tract by lateral approach may potentially play a fundamental role in the future. However, more long-term followup and randomized controlled trials are necessary to assess its efficacy and durability.

\section{Reference}

1. Ye F, Tang C, Wang D, Zheng S (2015) Early experience with the modificated approach of ligation of the intersphincteric fistula tract for high transsphincteric fistula. World J Surg 39:1059-1065. doi:10.1007/s00268-014-2888-1

2. Yassin NA, Hammond TM, Lunniss PJ, Phillips RK (2013) Ligation of the intersphincteric fistula tract in the management of anal fistula. A systematic review. Colorectal Dis 15:527-535

3. Limura E, Giordano P (2015) Modern management of anal fistula. World J Gastroenterol 21:12-20

4. Chen TA, Liu KY, Yeh CY (2012) High ligation of the fistula track by lateral approach: a modified sphincter-saving technique for advanced anal fistulas. Colorectal Dis 14:627-630 